\title{
Ethics in practice
}

\section{Genetic information: a joint account?}

Michael Parker, Anneke Lucassen

Does genetic information belong to the patient from whom it was obtained or to the whole family? The way in which this unavoidable question is answered has profound implications for the future of clinical practice in genetics

\section{Case history}

Helen Cross's 4 year old son has just had Duchenne's muscular dystrophy diagnosed. Genetic testing confirms the diagnosis and shows that she is a carrier for the mutation. Mrs Cross's sister, Penelope Yates, is 10 weeks pregnant. Mrs Yates's obstetrician referred her to the genetics team after she told him that her nephew had speech and development delay. She told him that although she was not close to her sister and had not discussed it with her, she was concerned about the implications for her own pregnancy. In her discussions with the clinical geneticist (who did not know at this stage that both sisters were patients in the same clinic) Mrs Yates made it clear that she would consider terminating a pregnancy if she knew that the fetus was affected with a serious inherited condition.

Speech and development delay are features of several conditions and would not of themselves indicate carrier testing for Duchenne's muscular dystrophy. In addition, because the Duchenne gene is large and several possible mutations exist, testing without information about which mutation is responsible for the nephew's condition is unlikely to be informative.

At her next meeting with her clinical geneticist, Mrs Cross says that she knows that her sister is pregnant and that she understands that her sister's baby could be affected. She says that she has not discussed this with her sister, partly because they don't really get on but also because she suspects that if her sister were to find out, and if the fetus turned out to be affected, she would terminate the pregnancy. Mrs Cross feels strongly that

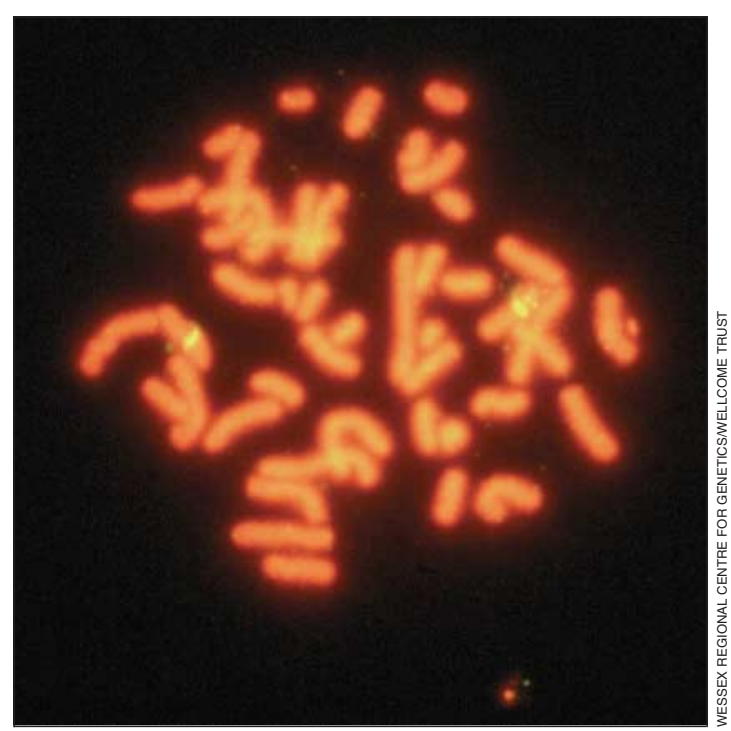

Chromosomes of female carrier of Duchenne's muscular dystrophy

\section{Duchenne's muscular dystrophy}

Duchenne's muscular dystrophy is a severe, debilitating, and progressive muscle wasting disease. Affected children become confined to a wheelchair by their early teens and usually die in their 20 s. It is an X linked recessive genetic condition, and although girls carry the gene, they are not (with rare exceptions) affected. Women who are carriers have a $50 \%$ chance of passing it on to their sons.

this would be wrong. She knows that her sister does not share her views, but Mrs Cross says she has thought long and hard about the issues and has decided that she wants her test results and information about her son to remain confidential.

\section{The issues}

At their regular team meeting, clinicians and counsellors say that they feel they have a duty of care to both sisters. But they are not sure what to do. To tell Mrs Yates would be to breach Mrs Cross's confidentiality and might undermine trust in the relationship between her and the team. On the other hand, Mrs Yates has a 1 in 12 chance (without her carrier status being confirmed) of having an affected child. (This risk is based on the fact that the condition is X linked recessive combined with the fact that there is a one third chance that the mutation in Mrs Cross was spontaneous and, hence, a two thirds chance that it was present in the sisters' mother.) A test would enable Mrs Yates to make a more informed reproductive choice. The team feels that not offering her the test would deny her access to important familial information.

\section{What are the options?}

The decision about how to deal with this case depends on how we view information produced as the result of a genetic test. Is it "personal" information, which a patient may sometimes have an obligation to share with other members of my family-for example, if its release will enable them to avoid serious harm? Or, is it essentially familial information, drawn from a kind of joint account, which a patient may sometimes have a right to withhold from other family members-for example, if its release would cause harm to the patient? It is uncertainty about which of these two models ought to apply in practice that lies behind current confusion about concern for individuals and families in genetic testing. This uncertainty arises because there are increasing numbers of cases, such as the one
This is the first article in an occasional series, edited by Michael Parker and Julian Savulescu, analysing ethical issues that confront health professionals in daily practice

Oxford Genetics Knowledge Park, Ethox Centre, University of Oxford, Oxford OX3 7LF

Michael Parker reader in medical ethics

Wessex Clinical Genetics Service, Genetics Service

Princess An Hospital, Southampton SO16 5YA

Anneke M Lucassen senior lecturer Correspondence to: M Parker

BMJ 2004;329:165-7 
described above, in which these two models require mutually exclusive courses of action.

\section{Personal account model}

On the usual reading, let us call this the "personal account model," this is a case about patient confidentiality and its limits-about whether it is ever morally acceptable for a clinician to breach a patient's confidentiality in the interests of others. Respect for confidentiality is a long and firmly established tradition in medicine. ${ }^{3}$ Although limits to such confidentiality and circumstances in which it should be breached have long been recognised, ${ }^{4}$ these exceptions serve only to highlight the assumption that information divulged by patients to their doctors is personal and should generally be treated as confidential. From this viewpoint, the key ethical question in the case above is whether the foreseeable harms to Mrs Yates of non-disclosure are sufficiently serious to justify breaching Mrs Cross's confidentiality. ${ }^{5}$

Perhaps the most important ethical justification underpinning respect for confidentiality arises out of respect for patient choice. It is widely accepted that competent patients should have control over decisions concerning their own medical care, to the extent that they have a well established right to refuse even life saving treatment. It is an implication of respect for patient choice that they should also have a right to decide what happens to information given by them to their clinician. ${ }^{6}$

A further justification for respecting patient confidentiality arises out of concern for the consequences of not so doing. Patients talk to health professionals because they trust them to keep their confidences. Breaches of confidentiality may undermine trust in the doctor-patient relationship. If Mrs Cross's confidentiality were breached she might lose trust in her doctor and therefore not get the support she needs in caring for her son. If such breaches of confidentiality were to become commonplace or well known, a more widespread lack of trust in health professionals might develop. Other patients might think twice about coming forward for investigation or treatment and miss out on important advice and care.

One of the advantages of the personal account model is that it is consistent with good practice in most areas of medicine. It takes patient wishes seriously and, despite its emphasis on respect for patient choice and confidentiality, is also able to take into account legitimate concern for the safety and wellbeing of others. It does so from a default position in which patient information is to be kept confidential unless there is a strong reason for it to be disclosed. The fact that the burden of proof in such cases rests with those who wish to breach confidentiality means that this model is at the core of patient centred medicine.

\section{Joint account model}

Nevertheless, this case can be read differently. On this alternative reading, let us call this the "joint account model," genetic information is shared by more than one person, much like information about a joint bank account. From this viewpoint, the ethical problem presented by Mrs Cross's request is not about the appropriate limits to confidentiality but is analogous to me asking my bank manager not to reveal information about a joint account to my fellow account holders. The problem the clinician faces is not when to respect confi- dentiality but what, if anything, would justify excluding others from the joint account? Whereas on the personal account model the default position is an assumption of confidentiality, on the joint account model it is assumed that information should be available to all account holders unless there are good reasons to do otherwise.

Practical implications of a joint account reading might include the routine storage of genetic information of relevance to other family members in a family registry. Health professionals would be able to access the information to construct family histories and to facilitate presymptomatic testing for family members who needed it. The burden of proof would lie with those wishing to exclude other family members from such information. As with the personal account model, the kind of reasons justifying divergence from usual practice would include foreseeable serious harms. However, in this model, the key to whether Mrs Cross's information would be shared with Mrs Yates would primarily be whether disclosure would be likely to cause harm to Mrs Cross, not whether non-disclosure would harm Mrs Yates.

Perhaps the strongest ethical principle in favour of the joint account model is that of justice, or perhaps reciprocity. Genetic information is, spontaneous mutations aside, essentially and unavoidably familial in nature. It is this feature of genetics that allows individuals to benefit from genetic testing and diagnosis. ${ }^{7}$ When a patient attends a genetic clinic, or discusses genetics with his or her general practitioner, a family history will be constructed, drawing on familial information about diseases and illness supplied by the patient about other family members, often without their consent. In many cases an extensive family history is needed to assess the usefulness of genetic testing. ${ }^{8}$ Given this, there is no obvious reason why one family member should be able to benefit and yet, at the same time, be allowed to exclude others from access to such benefits.

A further justification for the joint account model arises out of the benefits to be gained and harms to be avoided by routinely sharing genetic information. The current application of the personal account model, and of strict confidentiality, means that many potential benefits of genetic testing are untapped. Family members who might otherwise have benefited from testing, surveillance, or reassurance do not come forward because they are unaware of their family history. In addition, when relatives who were not informed about their risk develop symptoms or become aware of their family history, and that this was withheld from them, they may lose trust in their doctors. More generally, if it becomes widely known that information of this kind is being routinely withheld, at the request of affected family members, it may lead to a more widespread crisis of trust in the clinical genetics service and possibly legal action.

One additional advantage of the joint account model is that it is consistent with the nature of practice in clinical genetics. Geneticists work with families. ${ }^{2}$ This means that geneticists often come to know and to feel a sense of responsibility for several members of the same family. The joint account model takes seriously the familial nature of genetic information and clinical genetics and offers the possibility of broad access to the benefits of testing, where this does not cause serious harm to the index patient. 


\section{Conclusions}

Should the results of genetic tests be considered personal or familial information? This decision has important implications for clinical practice. In cases where the foreseeable harms of disclosure, or of non-disclosure, are serious, the two models agree. The implications of most genetic tests used in practice are, however, unlikely to meet the standard of serious harm required for a deviation from usual practice on either model, and in such situations, the models require us to pursue opposing courses of action. In the above case, the personal account model requires us to respect $\mathrm{Mrs}$ Cross's confidentiality but the joint account model requires us to make the information available to clinicians, such as Mrs Yates's geneticist, for the care of other family members..

Which of these models should apply in practice? The personal account model has much to recommend it, including consistency with good practice in other areas of medicine. Nevertheless, the familial nature of genetics, combined with the fact that the two models produce differing conclusions only in cases where the harms of disclosure are not serious to either party, suggests that justice demands the routine sharing of the benefits of genetic information except in exceptional circumstances.

Changing to a joint account model is of course controversial. It would be essential to inform those using genetic services at an early stage about the way in which the information resulting from such investigations was to be used. It would also require agreement about what is to count as a sufficiently serious harm to index patients to justify non-disclosure. For any change of practice to be acceptable, the appropriate standard of harm would need to be set low. That is, there would need to be only a small risk of harm to the index patient for disclosure to be ruled out. In many cases, therefore, adoption of the joint account model would make little difference to current practice. Nevertheless, adopting this model would mean that where there were no good reasons to do otherwise-that is, in most cases, genetic information would be available for use in the care and treatment of all family members, which is currently not the case.

Ethics in Practice is a bi-monthly series of case based papers, jointly written by ethicists and health professionals, examining ethical issues that confront health professionals in daily practice. The series is edited by Michael Parker, reader in medical ethics

\section{Summary points}

Clinical geneticists often find themselves with differing responsibilities to members of the same family

Currently genetic information is considered personal, putting the emphasis on patient confidentiality

Genetic testing is usually done only after assessing family history, and the results could be viewed as belonging to the family-the joint account model

Under such a model the patient would have to be at risk of serious harm to justify not sharing information

A joint account model would extend the benefits of testing when there is no risk of serious harm to index patients or their relatives

at the Ethox Centre, University of Oxford (michael. parker@ethox.ox.ac.uk) and Julian Savulescu of the Oxford Uehiro Centre for Practical Ethics.

Contributors and sources: Michael Parker has for the past four years been running a monthly ethics discussion forum at the Oxford Regional Genetics Unit helping health professionals to explore the ethical issues arising in their day to day practice. This led to the establishment, with Anneke Lucassen, of the Genetics Club, a three times yearly national forum for members of clinical genetics teams. Both authors have written widely on ethical issues in genetics (www.genethicsclub.org).

Competing interests: None declared.

1 Rose P, Lucassen A. Practical genetics for primary care. Oxford: Oxford University Press, 1999:134.

2 Parker M, Lucassen A. Concern for individuals and families in clinical genetics. J Med Ethics 2003;29:70-4.

3 General Medical Council. Confidentiality: protecting and providing information. http://www.gmc-uk.org/standards/secrethtm (accessed 8 Mar 2004).

4 American Society of Human Genetics Social Issues Subcommittee on Familial Disclosure. Professional disclosure of familial genetic information. Am J Hum Genet 1998;62:474-83.

5 Knoppers B, Wertz DC, Chadwick R, Penchaszadeh VB, LeBris, S. DefinKnoppers B, Wertz DC, Chadwick R, Penchaszadeh VB, LeBris, S. Defin-
ing "serious" disorders in relation to genetic services: who should decide? ing "serious" disorders in relation to ge

6 Human Genetics Commission. Inside information: balancing interests in the use of personal genetic data. London: HGC, 2002:47.

Knoppers B. Genetic information and the family. Trends Biotech 2002;20:85-6.

8 Rose P. Taking a family history. In: Rose P, Lucassen A. . Practical genetics for primary care. Oxford: Oxford University Press, 1999:57-75.

\section{One hundred years ago}

\section{The sanitation of Panama}

The Committee on Medical Legislation of the American Medical Association, consisting of Drs. C. A. L. Reed of Cincinnati, Wm. L. Rodman of Philadelphia, and Wm. H. Welch of Baltimore, has addressed a memorandum to President Roosevelt, making strong representations as to the need of vigorous measures being adopted to prevent as far as possible outbreaks of disease among the labourers employed in the construction of the Panama Canal. They urge that a representative of the medical profession should be appointed a member of the Canal Commission, and that Colonel William C. Gorgas, Surgeon United States army, should be chosen for the purpose. The Committee points out that "under both of the French administrations at the isthmus, the engineering problems themselves, to the chagrin of the medical profession of the world, failed of accomplishment largely through the frightful mortality among officers and labourers consequent upon lack of authority on the part of medical officers entrusted with the work of sanitation; that the same conditions of insalubrity exist now that existed then, and that consequently the sanitary problems are to be recognized as second in importance, if second at all, only to those connected with the engineering department."

(BMJ 1904;i:685) 